\title{
Design and usability testing of an in-house developed performance feedback tool for medical students
}

\author{
Yadira Roa Romero ${ }^{1}$, Hannah Tame ${ }^{1 *} \mathbb{D}$, Ylva Holzhausen², Mandy Petzold ${ }^{1}$, Jan-Vincent Wyszynski ${ }^{1}$, Harm Peters ${ }^{2}$, \\ Mohammed Alhassan-Altoaama', Monika Domanska ${ }^{3}$ and Martin Dittmar ${ }^{3}$
}

\begin{abstract}
Background: Feedback is essential in a self-regulated learning environment such as medical education. When feedback channels are widely spread, the need arises for a system of integrating this information in a single platform. This article reports on the design and initial testing of a feedback tool for medical students at CharitéUniversitätsmedizin, Berlin, a large teaching hospital. Following a needs analysis, we designed and programmed a feedback tool in a user-centered approach. The resulting interface was evaluated prior to release with usability testing and again post release using quantitative/qualitative questionnaires.

Results: The tool we created is a browser application for use on desktop or mobile devices. Students log in to see a dashboard of "cards" featuring summaries of assessment results, a portal for the documentation of acquired practical skills, and an overview of their progress along their course. Users see their cohort's average for each format. Learning analytics rank students' strengths by subject. The interface is characterized by colourful and simple graphics. In its initial form, the tool has been rated positively overall by students. During testing, the high task completion rate (78\%) and low overall number of non-critical errors indicated good usability, while the quantitative data (system usability scoring) also indicates high ease of use. The source code for the tool is open-source and can be adapted by other medical faculties.

Conclusions: The results suggest that the implemented tool LevelUp is well-accepted by students. It therefore holds promise for improved, digitalized integrated feedback about students' learning progress. Our aim is that LevelUp will help medical students to keep track of their study progress and reflect on their skills. Further development will integrate users' recommendations for additional features as well as optimizing data flow.
\end{abstract}

Keywords: Assessment feedback, Usability testing, Formative and summative assessment, Learning analytics, EPAs

\section{Background}

Feedback is an essential element of the educational process [1]. Studies [2, 3] show that good feedback practices may strengthen students' self-regulative ability. Based on the 7 principles of good feedback practices [2],

\footnotetext{
* Correspondence: hannah.tame@charite.de

'Quality Assurance in Education, Charité - Universitätsmedizin, Berlin, 10117 Berlin, Germany

Full list of author information is available at the end of the article
}

feedback should: 1) help to define good performance, 2) facilitate self-reflection, 3) deliver high-quality information to students about their learning, 4) encourage teacher and peer dialogue, 5) provide positive motivational beliefs and create self-esteem, 6) close the gap between current and desired performance, 7) provide instructors with information to shape their teaching. In addition to knowledge-based feedback delivered by examinations and grades - the focus during traineeships is

(c) The Author(s). 2021 Open Access This article is licensed under a Creative Commons Attribution 4.0 International License, which permits use, sharing, adaptation, distribution and reproduction in any medium or format, as long as you give appropriate credit to the original author(s) and the source, provide a link to the Creative Commons licence, and indicate if changes were made. The images or other third party material in this article are included in the article's Creative Commons licence, unless indicated otherwise in a credit line to the material. If material is not included in the article's Creative Commons licence and your intended use is not permitted by statutory regulation or exceeds the permitted use, you will need to obtain permission directly from the copyright holder. To view a copy of this licence, visit http://creativecommons.org/licenses/by/4.0/ The Creative Commons Public Domain Dedication waiver (http://creativecommons.org/publicdomain/zero/1.0/) applies to the data made available in this article, unless otherwise stated in a credit line to the data. 
on performance-based feedback. In an ideal context, feedback is a continual process between teacher and student. Despite its importance, most (medical) trainees feel that they do not receive adequate feedback, and when they do, the process is not effective [4]. This is in line with similar observations [5] which point to the fact that often there is no appropriate time and place for feedback sessions in medical training. However, effective feedback also affects metacognition, self-directed learning and self-awareness, and these competencies are in turn important for medical students' learning progress [6].

The necessity for the development of a feedback tool for the modular curriculum of medicine (MCM) became clear over the course of several accreditation procedures and evaluations of the degree programme by students, who expressed the need for reliable and structured feedback on their learning progress. In recent years, the Charité has piloted projects to introduce online feedback for medical students. An e-portfolio system offering a variety of features to stimulate learning was trialed using Wordpress (Avila et al., 2016 [7]). A later EU cooperation with 16 other universities aimed to combine feedback from Entrustable Professional Activities (EPAs, [8, 9] together with assessment data using Learning Analytics (LA) into an e-portfolio for workplace-based assessment (Holzhausen et al., 2019 [10]). Due to both the specific nature of the Charité medical curriculum in addition to the cost factor of purchasing external software, the faculty opted to create an in-house tool. The aim was to integrate assessment results, both summative (legally binding, determining whether a necessary standard has been reached) and formative (primarily to guide learning), together with EPA evaluations, and using learning analytics, provide feedback to students on their individual progress.

Software usability is key to achieving acceptance and making an impact on the target learner population, [1115]. Maintaining a strong user-centered design approach during development helps to maximize usability $[16,17]$. Based on this evidence, we ensured that the development and implementation process saw a strong, early focus on user needs. In the following we report on the design and usability testing of the new feedback tool.

\section{Implementation}

Development process and prototype testing

The development of the feedback tool LevelUp was characterized by iterative feedback loops between technical developers, project managers and medical student users at each development stage (Fig. 1). In the following, we elaborate on studies conducted as part of the research and prototyping stages, specifically a requirements analysis (study A) and usability testing (study B).

\section{Study A) Requirements analysis (research stage)}

An online requirements analysis questionnaire was conducted to identify student needs for better feedback on their learning progress (attachment A). This was sent to students (2nd semester and above) on the undergraduate medical curriculum at the Charité in 2017 (total $n=$ 2974). Students were asked if they wanted more feedback on their learning progress and if they would use a feedback tool for this purpose (5-point scale ranging from $1=$ strongly agree to $5=$ strongly disagree). In addition, a categorical item elicited students' opinions on preferred features and functions.

\section{Development process}

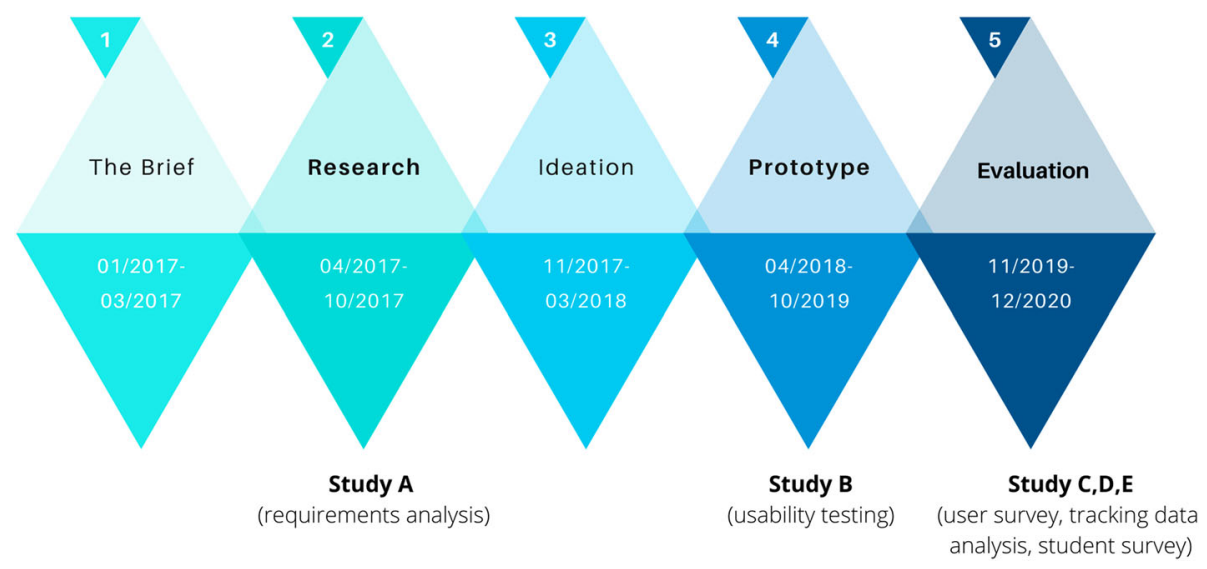

Fig. 1 Development timeline for LevelUp 


\section{Requirements analysis results}

In total, 1032 students participated (response rate $=34 \%$, mean age of $25(\mathrm{SD}=4), 65 \%$ female). $50 \%$ of students expressed a desire for more feedback on their learning progress $(M=2.6 ; S D=1.1)$ and $63 \%$ were interested in using a feedback tool which incorporated formative and summative feedback $(M=2.3 ; S D=1.2$, see Fig. 2$)$. In response to the question of which features an online feedback tool should contain, $80 \%$ of students wanted a mode to identify their strength and weaknesses, $72 \%$ a comprehensive overview of all exam results, and $66 \%$ more feedback on their progress in clinical skills (see Fig. 3).

Based on the results of study A, we firstly designed paper prototypes for the new tool. Medical students were continuously involved in the development of several prototype versions to ensure a good match to their needs. Once a satisfactory prototype had been created, programming began on a digital prototype.

\section{Technical development following paper prototyping}

The front end of the tool was programmed in React and Redux, using ReactJS as a framework. The back end is covered by a PHP-based application using the Symfony framework and a relational database, where assessment results are imported, computed and stored in the same way as user actions.

Data security and confidentiality was an important aspect in designing the platform. It is crucial that only students can access their own data and that even in case of a data breach, no personal data can be accessed. We achieved this by not saving any personal data on the live server. Instead, we create personal hashes on a separate internal server, which has access to all personal data. On the live server, all assessment results are connected only to the personal hash. The hash can only be re-created directly after login with the personal data given by the identity provider. A data protection concept for the development of the tool, which also covered usability testing during the pilot phase of the project, was approved by the office for data protection at the Charité.

In the following we describe the testing of the prototype tool with medical students.
Study B) Usability testing (prototype \& iteration stage)

This study followed the commonly recommended approach of using multiple usability measures and collected both subjective, self-reported data as well as objective data obtained by recording and analyzing the interactions of medical students with the software (attachment B).

The development team conducted the test using a prototype laptop version of LevelUp. Camtasia software (TechSmith) captured the participant's voice (audio input), comments, navigation choices and the click paths, in a think aloud approach.

Twenty-two medical students (mean age 23.8 years, 14 females (63\%) participated, who were equally distributed among semesters 2-11. Prior to completing the tasks, participants were asked about their expectations for a feedback tool. During the session, the test administrator explained the testing procedure and asked the participant to complete a brief background questionnaire. During the test, the task completion rates (in \%), time on task (in s.) and the number of non-critical errors were recorded (non-critical errors are errors that do not prevent successful completion of the task and the scenario). Overall satisfaction with the tool and the experience were measured by qualitative feedback at the end of the usability test.

\section{Statistical analysis}

All statistical analyses were carried out using SPSS 25 [18]. Descriptive statistics show mean (M) and standard deviation (SD).

\section{Results of usability testing}

Background information The interviews revealed that $96 \%$ of students wanted more feedback on their learning progress $(N=21)$ and that $86 \%$ already used commercial and non-commercial online self-assessment tools $(N=$ 19) to compensate this lack of feedback.

Task completion success rate Averaged over all tasks and participants, the task completion success rate was $78 \%$. Many tasks were carried out successfully (see Table 1). Notable was the very low completion rate (5\%)

\section{Agreement ratings (Q1 N=1032 / Q2 N=1021)}

\begin{tabular}{|c|c|c|c|c|c|}
\hline I fully agree $\square$ I agree $\square$ neither nor & I disagree & I fully disa & & & \\
\hline $\begin{array}{l}\text { Q1: I would like to have more feedback on my } \\
\text { learning progress }\end{array}$ & $19 \%$ & $31 \%$ & $24 \%$ & & $23 \%$ \\
\hline $\begin{array}{l}\text { Q2: I would use an online feedback tool to } \\
\text { visualize my learning progress }\end{array}$ & $27 \%$ & $37 \%$ & & $17 \%$ & $14 \%$ \\
\hline
\end{tabular}

Fig. 2 Study A) Result of students' ratings in the requirements analysis regarding the need for feedback and expected use of a feedback tool 


\section{Desired features of an online feedback tool (MCQ, \%)}

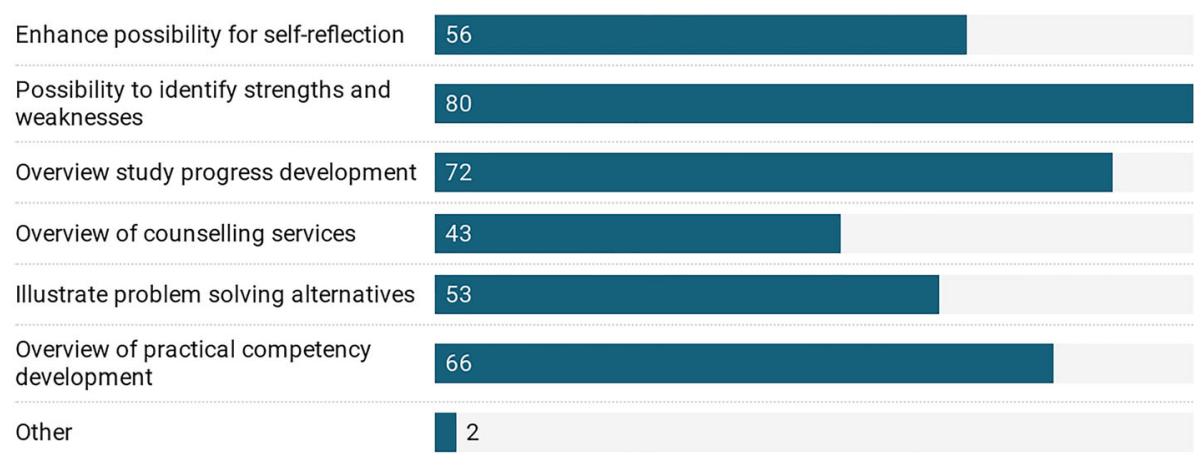

Fig. 3 Study A) Desired features for a feedback tool, student responses

for Task 10, which required students to find a number of professional activities listed in the area of EPAs.

Some tasks were inherently more difficult to complete than others, which is reflected by the average time spent on each task. On average, participants spent $40 \mathrm{~s}(\mathrm{SD}=$ 24) on the completion of each task. The number of errors depends on the complexity of the task. Participants made the most non-critical errors in task 9 and 5. Task 4 showed the least number of errors.

Redesign following study B The usability test identified 2 main issues based on participants' completion rates and time on task. The first was a lack of understanding of both the theoretical concept and implementation of the EPA feature as presented on the tool. Participants showed reduced completion rates for both EPA tasks,

Table 1 Overview of usability test data over 12 tasks. SD = standard deviation

\begin{tabular}{llll}
\hline \multicolumn{3}{l}{ Averaged task completion rate and time on task $(\boldsymbol{N}=\mathbf{2 2})$} \\
\hline Task & $\begin{array}{l}\text { Task } \\
\text { Completion }\end{array}$ & $\begin{array}{l}\text { Time on Task } \\
(\mathbf{s e c}) \\
+/- \text { SD }\end{array}$ & $\begin{array}{l}\text { Avg. Number of errors } \\
\text { +/- SD }\end{array}$ \\
\hline 1 & $91 \%$ & $60+/-30$ & $0.45+/-0.96$ \\
2 & $100 \%$ & $40+/-24$ & $0.10+/-0.31$ \\
3 & $82 \%$ & $61+/-33$ & $0.64+/-0.90$ \\
4 & $100 \%$ & $15+/-13$ & $0+/-0$ \\
5 & $73 \%$ & $58+/-29$ & $1.32+/-1.20$ \\
6 & $73 \%$ & $37+/-18$ & $0.95+/-0.97$ \\
7 & $91 \%$ & $24+/-15$ & $0.36+/-0.66$ \\
8 & $91 \%$ & $22+/-21$ & $0.32+/-0.57$ \\
9 & $77 \%$ & $67+/-35$ & $1.41+/-1.82$ \\
10 & $5 \%$ & $37+/-25$ & $0.9+/-0.44$ \\
11 & $55 \%$ & $39+/-27$ & $0.91+/-0.53$ \\
12 & $100 \%$ & $23+/-17$ & $0.22+/-0.52$ \\
\hline
\end{tabular}

and comments revealed a need for better orientation. The EPA-feature redesign focused on resolving these issues. We firstly reduced the complexity of the metrics, using 3 main scores distinguished by spacing and colour. The second issue addressed a more general problem of information architecture and graphic visualizations on the prototype tool, and we concluded that the navigation click paths needed simplifying. We redesigned the navigation structure by introducing "cards" on the dashboard page, and enhanced the discoverability of call-to-action buttons. We also reduced the complexity of graphs and bar charts. Following redesign the tool was released to all students.

Usability evaluation following release - methods The final design of LevelUp was evaluated using surveys following release. Two questionnaires addressed usability of the tool amongst both LevelUp users and students who had not yet used the platform.

Study C Since January 2020, registered users have had the opportunity to take part in an online survey to evaluate their experiences with the platform (attachment $\mathrm{C}$ ), accessed exclusively via a link on the dashboard page. A questionnaire including standard usability and website experience measurement criteria, the System Usability Scale (SUS) [19], a 7-point Likert scale ranging from $1=$ strongly agree to $7=$ strongly disagree) was chosen. The 7-point scale selected for psychometric reasons [20] was converted to 5 points for the SUS calculation. In order to assess the intention to revisit the website [21], further items were applied. These questions were set in rating scale format (7-point Likert scale ranging from $1=$ strongly agree to $7=$ strongly disagree). A single item (5point scale ranging from $1=$ strongly agree to $5=$ strongly disagree) assessed the overall impression of the platform [22]. 
Study D From January - March 2020, we evaluated students' experiences with LevelUp via an additional online questionnaire (attachment D) sent out to all MCM students. Two dichotomous single choice questions determined whether students were already aware of the tool and had used it. Respondents were classified as 'user', or one of two types of 'non-user': 'type 1 non-user' (aware of tool) and 'type 2 non-user' (not yet aware of tool). Based on this, students were asked open-ended questions to address the features they liked most and to elicit recommendations or improvements for LevelUp (user group), as well as general expectations and desired features for a feedback tool (non-user group).

A quantitative and qualitative analysis of open-ended questions on the current features, suggested improvements as well as obstacles to using LevelUp was carried out. The resulting comments were evaluated with regard to their main themes, and further categorized qualitatively into sub-themes. The overall number of comments, and comments relating to specific categories, were also assessed quantitatively to rank themes in order of priority.

\section{Results: tool release and evaluation}

The final design for LevelUp was released for all medical students in November 2019. The feedback tool is a browser app for desktop or mobile. Students log in using their student email address and matriculation number. LevelUp is currently available in German and a demonstration version can be viewed at https://levelup.charite. de. On signing in, the user is presented with a personal dashboard page displaying clickable feature cards, from which the tool can be navigated (see Fig. 4). In addition to graphic visualizations of all assessment results, including markers for the average of their cohort, users are able to garner the following feedback on their progress:
- Detailed multiple choice (MCQ) exam results including feedback on all questions and answers with solutions

- Detailed visualization of their knowledge growth with the aid of the Progress Test Medicine (PTM) feature

- A personal checklist of requirements fulfilled to progress onto the next stage of their course

- A review of acquired practical competencies (EPAs) to assist students in preparing for their medical clerkships. Students can enter self-evaluations in the form of a score on a supervision scale for individual professional activities, as well as request evaluations from their teachers

- Personal strengths ranked according to subject area

The specific features of LevelUp are detailed in Table 2.

In the following we report on evaluation results following initial release (studies $\mathrm{C}, \mathrm{D}$ and $\mathrm{E}$ ).

\section{Study C): Dashboard survey}

Responses were analyzed in March 2020 and again in April 2021. A sample of 22 users (semesters 2-9) gave feedback via the dashboard survey in the initial analysis. The overall impression of the platform LevelUp was rated positively $(\mathrm{M}=1.8, \mathrm{SD}=0.9)$ by all participants. Students' intention to use and revisit rating $(M=2.2$, $\mathrm{SD}=1.3$ ) showed that students have a strong intention to revisit the platform. The mean SUS rating of 81.2 $(\mathrm{SD}=14.1)$ indicated a good usability of the platform LevelUp (a "good" SUS score is above 76 [23, 24]). In April 2021 we were able to re-analyze with 68 responses resulting in a mean SUS score of $79.5(\mathrm{SD}=15.1)$, intention to revisit as $2.5(\mathrm{SD}=1.5)$ and an overall rating of $2.0(\mathrm{SD}=0.9)$.

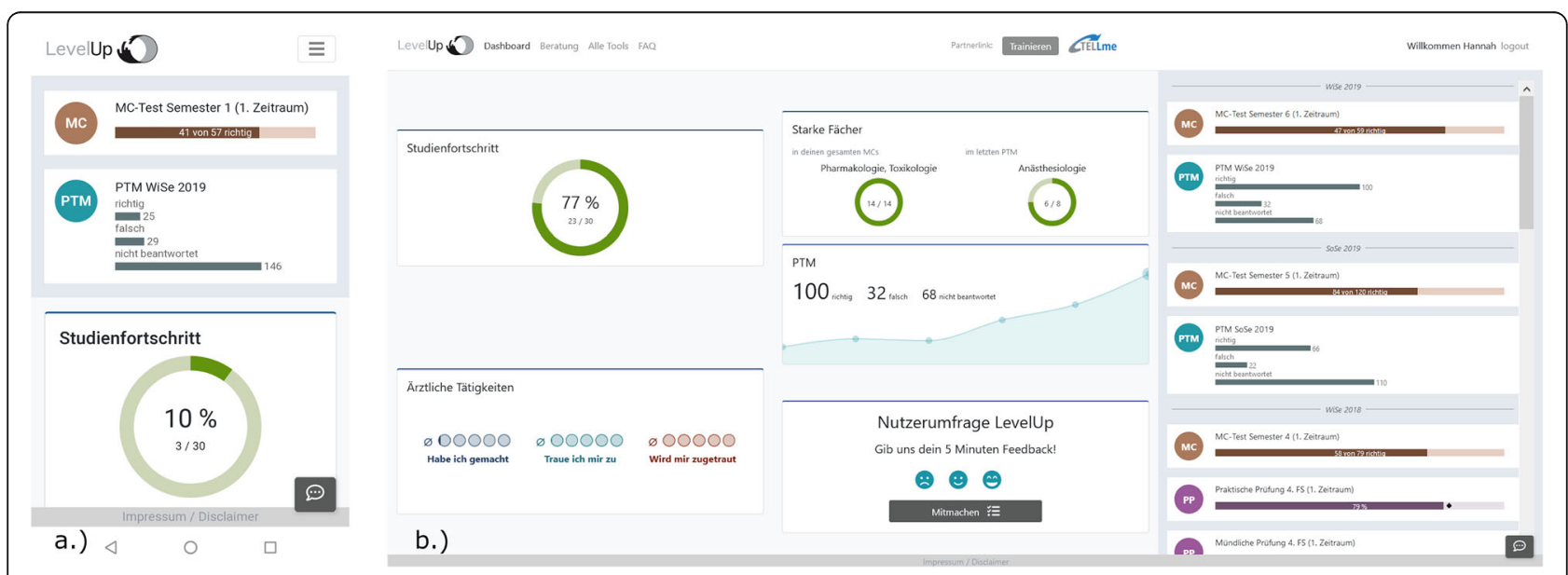

Fig. 4 LevelUp dashboard screenshot A mobile device $\mathbf{B}$ desktop 
Table 2 Overview of features

\begin{tabular}{|c|c|}
\hline \\
\hline Feature & $\begin{array}{l}\text { LevelUp features } \\
\text { Feature }\end{array}$ \\
\hline Dashboard & $\begin{array}{l}\text { Visually tracks, analyzes and displays } \\
\text { performance indicators and key data points to } \\
\text { monitor progress }\end{array}$ \\
\hline Study Progress Tracker & $\begin{array}{l}\text { Overview of study progress visualizing } \\
\text { milestones (e.g. clerkships) and completed } \\
\text { modules and exams }\end{array}$ \\
\hline Timeline & $\begin{array}{l}\text { Chronological overview of all completed } \\
\text { assessments }\end{array}$ \\
\hline $\begin{array}{l}\text { Detailed MCQ Exam } \\
\text { results }\end{array}$ & $\begin{array}{l}\text { Visualization of MCQ performance in } \\
\text { comparison to student cohort, subject and } \\
\text { module, with statistical details }\end{array}$ \\
\hline $\begin{array}{l}\text { Strengths and } \\
\text { weaknesses analysis }\end{array}$ & $\begin{array}{l}\text { Ranking of strengths and weaknesses } \\
\text { according to subject area, based on MCQ } \\
\text { exams and PTM }\end{array}$ \\
\hline $\begin{array}{l}\text { Practical competencies } \\
\text { (EPAs) }\end{array}$ & $\begin{array}{l}\text { Records the development of practical } \\
\text { competencies incl. self-assessment and evalu- } \\
\text { ation by teachers }\end{array}$ \\
\hline $\begin{array}{l}\text { Longitudinal overview } \\
\text { of PTM results }\end{array}$ & $\begin{array}{l}\text { Overview of longitudinal and cross-sectional } \\
\text { PTM performance per subject }\end{array}$ \\
\hline Advice services & $\begin{array}{l}\text { An overview of all advice services for students } \\
\text { at the Charité }\end{array}$ \\
\hline Online Tools & $\begin{array}{l}\text { Links to all useful tools and platforms for } \\
\text { students at the Charité }\end{array}$ \\
\hline
\end{tabular}

\section{Study D): Broad LevelUp evaluation survey}

In total a sample of 736 students participated (response rate $=22 \%,=24.7$ years $(\mathrm{SD}=4.6$ years $)$, female $=64.6 \%$, diverse $=1.6 \%$ ). In total, 223 students ( $30 \%$, user group) produced 138 responses to the open-ended question "How do you currently use LevelUp?". Two hundred forty-three students (33\%, non-users type 1 group) generated 92 responses overall according to the open-ended question "What features does a feedback tool need". Finally, 270 students (37\%, non-users type 2 group) made 81 comments in response to the question "What features would be beneficial to you in a feedback tool?" (see Fig. 5).

\section{Study E) Web analytics}

Matomo open-source web analytics software is used to analyze traffic on the platform, including clicks on each feature. Student registrations on the platform are documented, as well as the number of requests to loginrestricted features, which serves as a measurement of the frequency of use. In line with data protection regulations, this data cannot be assigned to specific users.

The number of registrations to the tool from semesters $1-10$ is currently 2219 ( $\mathrm{N}$ total $=3639)$. This number increases significantly with each new semester. According to Matomo, approx. 139,300 actions (clicks) by registered users were tracked in LevelUp between release in November 2019 and April 2021. Up to April
2021, there were a total of 36,450 visits, with users spending an average of $2 \mathrm{~min}$ on the site, and the average number of actions per visit 8 .

\section{Discussion \\ Interface usability}

The applied forms of usability testing (study B-D) indicated an overall ease of use and positive evaluation of the new platform. Features which were perceived to be difficult to understand were adapted and redesigned. Web analytics (study E) showing a high number of page visits since release indicate that students are using the new platform. The SUS-score of 79.5 suggests that LevelUp can be regarded as acceptable within the acceptability range $(70-100 \%)$. This score has also been associated with a verbal user rating of 'good' (score 72-85) according to other studies [24, 25]. However, the primary use of the SUS is to classify the ease of use of a website, it is not a diagnostic tool for identifying areas of improvement $[21,23,25,26]$. The qualitative comments from the survey (D) reiterate the high SUS-score.

\section{Value as a feedback tool and further development}

The majority of comments (study D) highlight that having a centralized site to find integrated formative and summative feedback about their study progress is key for most participants. The overall concept of LevelUp specifically focuses on the facilitation of self-reflection by collating and analyzing assessment results together with self-evaluations on a single platform. The study progress tracker, the statistical details on MCQ assessments and the PTM-feature give detailed information to students about their learning. LevelUp thus adheres to several principles of good feedback [2].

Improvements still need to be made to the tool. In particular, involving teachers and instructors in the feedback process will be a priority in the further development of the tool. Teachers could for instance use LevelUp to obtain feedback about their teaching, evaluations, assessments or MCQs they have created. An increase of bidirectional feedback may strengthen the general feedback culture within the faculty. LevelUp does not currently offer a function for qualitative data entry such as text and commentary, which would be a necessary further development if the above feature is to be realized.

There is evidence in the qualitative survey data that non-users who were not yet aware of LevelUp would appreciate features (e.g. study progress tracker and selfevaluation of practical competencies) that are already provided by LevelUp. Based on these findings, a current strategy to promote LevelUp through a wide range of channels (e.g. social media, posters) aims to boost registrations. 


\section{number of comments \\ Detailed exam results \\ Monitoring study progress \\ Strengths/weaknesses analysis \\ Exam practice, knowledge testing \\ Comparisons (Cohort, development) \\ Other}

How have you used LevelUp in your studies so far?

Qualitative and quantitative analysis of comments (users)

36

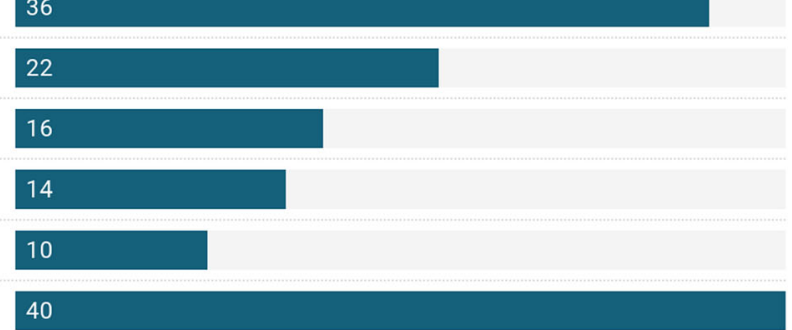

\section{What features would a feedback tool need to have for you to use it?}

Qualitative and quantitative analysis of comments (non-user-type 1)

number of comments

Exam practice and knowledge transfer

Easy to use/navigate

27

Clear design (visualisation of results, comparisons)

20

8

Additional information (instructions, introduction)

Reminder functions, notifications

Other

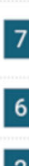

24

\section{What features would be benefical to you on a feedback tool?}

Qualitative and quantitative analysis of comments (non-user-type 2)

number of comments

Test knowledge, practice MC-questions

Overview of grades and performance

Easy to use, uncomplicated navigation

Reminder functions, notifications
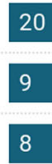

5

Integration of services and reduced number of platforms

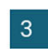

Other

Fig. 5 Study D) Broad student survey - results of qualitative commentary analysis with the main topics for the user group, non-user group type 1 and non-user group type 2

Further studies are needed to investigate the effects of the feedback tool in groups of regular users and nonusers amongst undergraduate medical students over the course of their degree and the effect on e.g. reducing exam drop-out rates. Registrations to the tool increase with each semester and we expect new students to grow used to using LevelUp throughout their studies. More senior students may be less inclined to use the tool due to its late introduction. The EPA feature becomes more relevant for senior students preparing for their clerkships, hence investigating usability for this target group and communicating the value of the new tool to senior students will be the focus of future iterations. Web analytics Matomo gathers information on the number of clicks on each feature, and analysis of this data over time will guide development of the tool. Students' 
recommendations for improvements will be garnered as part of a broad student survey in late 2021, continued analysis of the dashboard survey responses, as well as qualitative interviews to be carried out on campus. Optimizing the speed of data flow into the tool from assessments will further increase the tool's usefulness.

\section{Usability study limitations}

The usability study has limitations. Regarding Study C, in total 30 (including former paper prototype testing) students were involved in this process. This limits the generalizability of the results for larger student cohorts. Our results may also be limited by a selection bias due to the voluntary nature of the testing. The qualitative and quantitative survey data (B, D) yielded a much larger sample, arguably providing greater reliability.

Matomo web analytics software provides valuable statistics on visits to the tool. However, in line with data protection regulations, these statistics cannot be assigned to individual users. This means that we do not currently have sufficient information on particular groups of students, such as semester cohorts, and how they use the tool. A planned broad student survey in late 2021 will yield information on use of the platform per semester group.

\section{LevelUp as an adaptable, open-source software}

The source code for the platform was released under an open source licence in May 2020 and can be downloaded free at Github (see software availability). Institutions wishing to implement feedback software can adapt the system to meet their requirements with relatively few resources. The current implementation is not necessarily specific for the Charité, but specific for the given assessment formats. If, for example, MCQ tests with mapped tags such as subjects are a given assessment format, the data structure can already be used by other universities.

The aim of the open-source project is to create a more standardized and customizable software. Other faculties would nevertheless need to create import adapters for integrating the data of their specific assessment formats into the data structure of LevelUp. Currently, the user interface is only available in German, but can easily be translated.

\section{Conclusions}

The results of the usability test and online survey suggest that in its early release form, LevelUp is wellaccepted and fulfils a need for better feedback for students on the modular curriculum at the Charité. Students appreciate having an overview of the complete range of assessment results presented to them on a single, easy to use platform. The good usability of the tool means that it is likely students will return to the platform regularly. Data from repeated usability testing as well as broader student evaluation surveys will provide input for its continued development. Our long term aim for the tool is that it will provide high-quality online feedback for students as part of a strategy to close a perceived gap in feedback during their medical studies.

\section{Availability and requirements \\ Project name: LevelUp \\ Project home page: https://levelup.charite.de \\ Operating system(s): web-based application (Firefox, Chrome, Safari, MS-Edge) \\ Programming language: Front end: React and Redux, using ReactJS as a framework. Back end: PHP-based ap- plication using the Symfony framework and a relational database.}

License: GNU Affero General Public License v3.0 https://github.com/charite-studium-und-lehre

\section{Any restrictions to use by non-academics: none}

\section{Abbreviations}

MCM: Modular Curriculum of Medicine, the degree in medicine at Charité Universitätsmedizin, Berlin; MCQ: Multiple choice questions; PTM: Progress Test Medicine; EPAs: Entrustable Professional Activities; SD: Standard deviation; SUS: System usability scale

\section{Supplementary Information}

The online version contains supplementary material available at https://doi. org/10.1186/s12909-021-02788-4.

Additional file 1. Attachment A. Study A, general student survey 2017 (excerpt, questions on learning progress and feedback).

Additional file 2. Attachment B. Study B, pre-interview and usability tasks for LevelUp.

Additional file 3. Attachment C. Study C (dashboard user-questionnaire based on the System Usability Score (SUS).

Additional file 4. Attachment D. Study D, general student survey 2020 (excerpt, questions on the newly released LevelUp).

\section{Acknowledgements}

The authors thank Charité - Universitätsmedizin, Berlin, for its support. In particular, we are very grateful to Sandra Buron and the eLearning team for their technical advice and support during the usability test. We also wish to thank Miriam Alexander, Anne Franz, Anja Linke and Aleksandr Vashchenkov for their continuous help during the testing, as well as the students who voluntarily participated in the study. We extend our gratitude to the staff at the examinations dept. at the Charité: Susanne Werner, Alexander Mentzel, Sylke Langenbeck, Maren März, and the dept. of semester coordination, headed by Axel Schunk.

\section{Notes on contributors}

YRR is a psychologist (PhD) currently working on user experience and usability topics.

HT, MBA (Change Management), is a project manager in the Quality Assurance in Education team at the Charité.

$\mathrm{YH}, \mathrm{M} . \mathrm{Sc}$., is a research fellow and PhD student at the Dieter Scheffner Centre for Medical Education at the Charité.

MP is an educational scientist and leads the multi-professional team for Quality Assurance in Education at the Charité.

JWW, B.Sc. in Mathematics, is a software developer and MD who studied at the Charité. 
MAA is studying Engineering Informatics at the HTW University of Applied Sciences, Berlin.

$H P, M D, M H P E$, is an MD, Professor of Medical Education and Director of the Dieter Scheffner Centre for Medical Education at the Charité.

MDo and MDi are both full stack web developers and members of the IT dept. at the Charité

\section{Authors' contributions}

YRR, the main author, made significant contributions to the research design, data collection, data analysis and interpretation, and writing of the manuscript. HT contributed to the data collection and in particular the writing of the manuscript. YH contributed to the research design and the collection of the data. JWW, MD, MAA and MD were involved in software design, programming of the software and specific features. HP and MP contributed to the writing of the manuscript. All of the authors have critically reviewed and approved the final draft and are responsible for the content of the manuscript.

\section{Funding}

This study was fully funded by the Berliner Qualitäts- und Innovationsoffensive $(\mathrm{Q} I O)$ grant scheme. The funding body did not play a role in the in the design of the study, the collection, analysis, and interpretation of data, or in writing the manuscript. Open Access funding enabled and organized by Projekt DEAL.

\section{Availability of data and materials}

The data used and analyzed during the current study are available from the corresponding author upon reasonable request.

\section{Declarations}

\section{Ethics approval and consent to participate}

This study was conducted with permission from the Charite as a part of its program evaluation. Ethical approval was granted by the Ethics Committee at the Charité. The approval code is 0104-SP-18.

\section{Consent for publication}

Before the interviews and usability tests were conducted, participants gave informed written consent. The consent form was approved by the ethics committee.

\section{Competing interests}

Harm Peters is an editor for this journal. The other authors declare that they have no competing interests. The Charité has no intention to market this software commercially and has made the source code freely available on Github (see above Software availability).

\section{Author details}

'Quality Assurance in Education, Charité - Universitätsmedizin, Berlin, 10117 Berlin, Germany. ${ }^{2}$ Dieter Scheffner Center for Medical Education and Educational Research, Dean's Office of Study Affairs, Charité Universitätsmedizin, Berlin, 10117 Berlin, Germany. ${ }^{3}$ Business Division IT, Charité - Universitätsmedizin, Berlin, 10117 Berlin, Germany.

Received: 5 January 2021 Accepted: 10 June 2021

Published online: 23 June 2021

\section{References}

1. Van De Ridder JMM, Stokking KM, McGaghie WC, Ten Cate OTJ. What is feedback in clinical education? Med Educ. 2008;42(2):189-97. https://doi. org/10.1111/j.1365-2923.2007.02973.x.

2. Nicol D, MacFarlane-Dick D. Formative assessment and selfregulated learning: a model and seven principles of good feedback practice. Stud High Educ. 2006;31(2):199-218. https://doi.org/10.1080/03075070600572090.

3. Wiggins G. Seven keys to effective feedback. Educ Leadersh. 2012;70:10-6.

4. Ramani S, Krackov SK. Twelve tips for giving feedback effectively in the clinical environment. Med Teach. 2012;34(10):787-91. https://doi.org/10.31 09/0142159X.2012.684916.

5. Hesketh EA, Laidlaw JM. Developing the teaching instinct. Med Teach. 2002; 24(3):245-8. https://doi.org/10.1080/014215902201409911.
6. Hong WH, Vadivelu J, Daniel EGS, Sim JH. Thinking about thinking: changes in first-year medical students' metacognition and its relation to performance. Med Educ Online. 2015;20(1):27561. https://doi.org/10.3402/ meo.v20.27561.

7. Avila J, Sostmann K, Breckwoldt J, Peters H. Evaluation of the free, open source software WordPress as electronic portfolio system in undergraduate medical education. BMC Med Educ. 2016;16(1):1-10. https://doi.org/10.1186/ s12909-016-0678-1.

8. Ten Cate O. Entrustability of professional activities and competency-based training. Med Educ. 2005;39(12):1176-7. https://doi.org/10.1111/j.1365-2929.2 005.02341.X

9. Holzhausen Y, Maaz A, Renz A, Bosch J, Peters H. Development of entrustable professional activities for entry into residency at the Charité Berlin. GMS J Med Educ. 2019;36:Doc5.

10. Peters H, Holzhausen Y, Maaz A, Driessen E, Czeskleba A. Introducing an assessment tool based on a full set of end-of-training EPAs to capture the workplace performance of final-year medical students. BMC Med Educ. 2019;19:1-13.

11. Van Nuland SE, Eagleson R, Rogers KA. Educational software usability: artifact or design? Anat Sci Educ. 2017;10(2):190-9. https://doi.org/10.1002/a se.1636.

12. Sandars J. The importance of usability testing to allow e-learning to reach its potential for medical education. Educ Prim Care. 2010;21(1):6-8. https:// doi.org/10.1080/14739879.2010.11493869.

13. Sandars J, Lafferty N. Twelve tips on usability testing to develop effective elearning in medical education. Med Teach. 2010;32(12):956-60. https://doi. org/10.3109/0142159X.2010.507709.

14. Thoma B, Bandi V, Carey R, Mondal D, Woods R, Martin L, et al. Developing a dashboard to meet competence committee needs: a design-based research project. Can Med Educ J. 2020;11:e16.

15. Boscardin C, Fergus KB, Hellevig B, Hauer KE. Twelve tips to promote successful development of a learner performance dashboard within a medical education program. Med Teach. 2018;40(8):855-61. https://doi.org/1 0.1080/0142159X.2017.1396306.

16. Freire LL, Arezes PM, Campos JC. A literature review about usability evaluation methods for e-learning platforms. Work. 2012;41(SUPPL.1):103844. https://doi.org/10.3233/WOR-2012-0281-1038.

17. Chu A, Biancarelli D, Drainoni ML, Liu JH, Schneider Jl, Sullivan R, et al. Usability of learning moment: features of an e-learning tool that maximize adoption by students. West J Emerg Med. 2019;21(1):78-84. https://doi. org/10.5811/westjem.2019.6.42657.

18. IBM Corp. IBM SPSS statistics for windows. 2017.

19. Brooke J. SUS: a quick and dirty usability scale. In: Usability evaluation in industry: Taylor \& Francis Ltd; 1996. https://www.researchgate.net/publica tion/228593520_SUS_A_quick_and_dirty_usability_scale. Accessed 17 Apr 2021.

20. Finstad K. The usability metric for user experience. Interact Comput. 2010; 22(5):323-7. https://doi.org/10.1016/j.intcom.2010.04.004.

21. Moshagen M, Thielsch MT. Facets of visual aesthetics. Int I Hum Comput Stud. 2010;68(10):689-709. https://doi.org/10.1016/j.jijhcs.2010.05.006

22. Thielsch MT, Blotenberg I, Jaron R. User evaluation of websites: from first impression to recommendation. Interact Comput. 2014;26(1):89-102. https:// doi.org/10.1093/iwc/iwt033.

23. Kortum $\mathrm{P}$, Acemyan $\mathrm{CZ}$, Oswald FL. Is it time to go positive? Assessing the positively worded system usability scale (SUS). Hum Factors. 2020. https:// doi.org/10.1177/0018720819881556.

24. Lewis JR, Sauro J. The factor structure of the system usability scale. Lect Notes Comput Sci (including Subser Lect Notes Artif Intell Lect Notes Bioinformatics). 2009;5619 LNCS:94-103.

25. Lewis JR. The system usability scale: past, present, and future. Int J Hum Comput Interact. 2018;34(7):577-90. https://doi.org/10.1080/10447318.201 8.1455307.

26. Lewis JR. Measuring user experience with 3, 5, 7, or 11 points: does it matter? Hum factors. 2019. https://doi.org/10.1177/0018720819881312.

\section{Publisher's Note}

Springer Nature remains neutral with regard to jurisdictional claims in published maps and institutional affiliations. 